\title{
Endoscopic management of cystic duct stones and Mirizzi's syndrome: experience at an academic medical center
}

\section{다 (용}

\author{
Authors \\ Rishi Pawa', Robert Dorrell², Swati Pawa' \\ Institutions \\ 1 Department of Medicine, Section on Gastroenterology, \\ Wake Forest School of Medicine, Winston-Salem, North \\ Carolina, United States \\ 2 Department of Medicine, Wake Forest School of \\ Medicine, Winston-Salem, North Carolina, United States
}

submitted 30.3.2021

accepted after revision 10.8 .2021

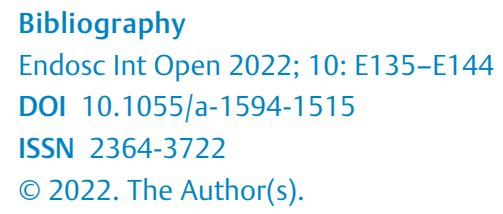
Commons Attribution-NonDerivative-NonCommercial License, permitting copying and reproduction so long as the original work is given appropriate credit. Contents may not be used for commercial purposes, or adapted, remixed, transformed or built upon. (https://creativecommons.org/licenses/by-nc-nd/4.0/)

Georg Thieme Verlag KG, Rüdigerstraße 14,

70469 Stuttgart, Germany

Corresponding author

Rishi Pawa, MD, Wake Forest University School of Medicine, Department of Medicine, Division of Gastroenterology Medical Center Boulevard, Winston-Salem, NC 27157, United States

Fax: +1-336-713-7322

rpawa@wakehealth.edu

\section{ABSTRACT}

Background and study aims Cystic duct stones (CDS) are challenging to treat with conventional ERCP techniques due to the small diameter and tortuous nature of the cystic duct. There have been limited studies focused on endoscopic management of CDS. We present our experience managing CDS endoscopically and demonstrate that new advances in endoscopic technology have rendered CDS easier to manage.

Patients and methods From 2013 to 2020, we prospectively maintained a database of patients undergoing endoscopic management of CDS. ERCP was performed in all patients, and if unsuccessful in removing stones, cholangioscopy with electrohydraulic lithotripsy (EHL) was utilized. All patients were followed in clinic for outcomes.

Results Of 5,123 ERCPs performed at our institution during the study period, 21 patients were diagnosed with CDS.Six patients were successfully treated with conventional ERCP alone. Cholangioscopy with EHL was used in 15 patients undergoing 18 procedures to achieve stone clearance. CDS clearance was achieved in all patients. There was one adverse event (post-ERCP pancreatitis). Spyglass DS was associated with a significant decrease in average procedure time in comparison to first-generation SpyGlass (89.3 vs. 54.4 minutes, $P=0.004)$. Thirteen patients $(87 \%)$ were discharged from the hospital within 24 hours. The median follow-up duration was 23.2 months.

Conclusions Endoscopy should be the preferred management strategy for CDS, especially in patients with prior cholecystectomy. Surgical outcomes have been associated with high patient morbidity and hospital length of stay. Our case series is the largest cohort of CDS patients successfully managed with cholangioscopy and EHL in the United States.

\section{Introduction}

The cystic duct, which connects the gallbladder to the common hepatic duct, is a tortuous channel susceptible to obstruction by cystic duct stones (CDS). These stones typically form in the gallbladder and migrate into the cystic duct. CDS can cause a spectrum of disease, ranging from biliary colic to cholecystitis to Mirizzi's syndrome (MS), in which the common hepatic duct is obstructed by inflammation surrounding the gallbladder or cystic duct [1]. Symptomatic CDS warrants intervention, which traditionally involves surgical cholecystectomy with distal ligation of the cystic duct in patients with an intact gallbladder. However, endoscopic procedures are available as an alternative to invasive surgery, especially in patients with prior cholecystectomy in whom surgical procedures can contribute to significant morbidity [2,3]. Although stone extraction by endoscopic 
retrograde cholangiopancreatography (ERCP) is technically challenging due to the anatomy of the cystic duct, cholangioscopy with lithotripsy (electrohydraulic or laser) is an innovative and effective intervention for CDS [4]. While this procedure has not yet been studied widely for CDS, a few case reports and case series demonstrate its ability to successfully facilitate CDS removal [5]. To our knowledge, this is the largest case series of endoscopic management of CDS in the United States. We report our experience within an academic hospital system and summarize the progression of endoscopic management of CDS with increased utilization of single operator cholangioscopy. These innovations have improved clinical outcomes for these patients and have made endoscopy the preferred intervention for CDS.

\section{Patients and methods}

Information on patients undergoing ERCP for management of CDS or MS at Wake Forest Baptist Medical Center from June 2013 to December 2020 was identified and prospectively stored in a secured database in accordance with our institutional review board (IRB number: 00000215). Patient data, including clinical presentation, laboratory values (i.e. liver function tests), diagnostic imaging, procedure details, adverse events (AEs), and clinical outcomes, were collected and retrospectively analyzed ( $\triangleright$ Fig. 1). Descriptive statistics were used for the analysis. Patient and procedure characteristics were presented with percentages (\%), mean and standard deviation (SD), and median and range.

All patients diagnosed with CDS or MS were consented for ERCP and cholangioscopy. ERCPs were performed under general anesthesia or monitored anesthesia care (supervised by an anesthesiologist). Antibiotic prophylaxis, most commonly with ciprofloxacin, was administered at the start of the procedure. Following cannulation of the bile duct, a cholangiogram was obtained, and cystic duct patterns were classified into three types based on the classification system proposed by Cao et al: Type 1 located on the right and angled up, Type 2 located on the right and angled down, and Type 3 located on the left and angled up [6]. A biliary sphincterotomy was performed and attempts were made to clear stones from the cystic duct using standard accessories (including stone extraction balloons and baskets). If unsuccessful, a cholangioscope (SpyGlass, Boston Scientific, Marlborough, Massachusetts, United States) was advanced over a guidewire through the working channel of a duodenoscope (Pentax, Tokyo, Japan) (\$ Fig. 2). Upon direct visualization of the CDS on cholangioscopy, electrohydraulic lithotripsy (EHL) was performed through the working channel of the cholangioscope (1.9 F probe and the Nortech Autolith system, Northgate Technologies, Inc, Elgin, Illinois, United States) to achieve stone fragmentation. Saline was used for irrigation through the SpyGlass irrigation channel. EHL was completed using a power of 90 watts and a frequency of seven shots per second. This process was repeated with gradual increase in frequency as necessary (maximum 10 shots per second). The stone fragments were subsequently removed using balloon sweeps and/or baskets ( $\mathbf{F i g . 3}$ ).

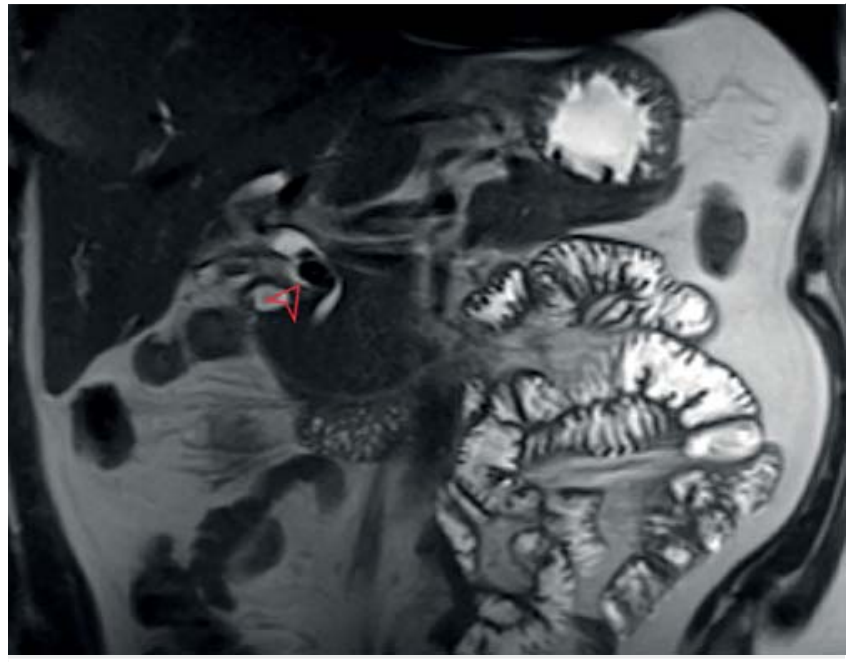

- Fig. 1 MRCP in a patient with prior cholecystectomy showing a 16-mm calculus (red arrowhead) at the junction of cystic duct and bile duct concerning for Type I Mirizzi's syndrome.
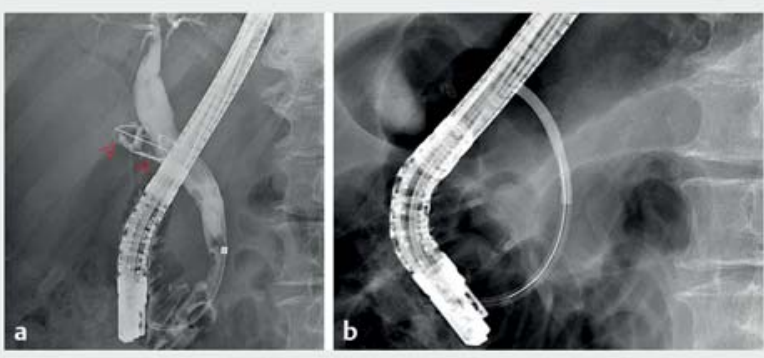

Fig. 2 a Cholangiogram showing two stones (red arrowheads) in the cystic duct. b Fluoroscopic image showing SpyGlass DS in the cystic duct.

The primary outcome was defined as complete cystic duct clearance, documented either by cholangiogram or direct visualization via cholangioscopy. The secondary outcome was procedure-related complications.Complications were recorded and graded according to the American Society of Gastrointestinal Endoscopy (ASGE) Lexicon criteria [7]. Patients were followed in an outpatient clinic for ongoing laboratory analysis and clinical outcomes after the procedure.

\section{Results}

Of the 5,123 ERCPs that were performed at our institution during the study period, 21 were performed for the removal of CDS or treatment of MS.Six patients (29\%) underwent successful extraction of CDS with traditional ERCP techniques. The remaining 15 patients (71\%) required cholangioscopy and EHL for direct stone visualization and extraction. Three of these patients were treated with first-generation SpyGlass (20132017), and 12 were treated with Spyglass DS (2017-2020). Two patients required more than one cholangioscopy session (a total of 5 cholangioscopies and $\mathrm{EHL}$ ) to remove the CDS 

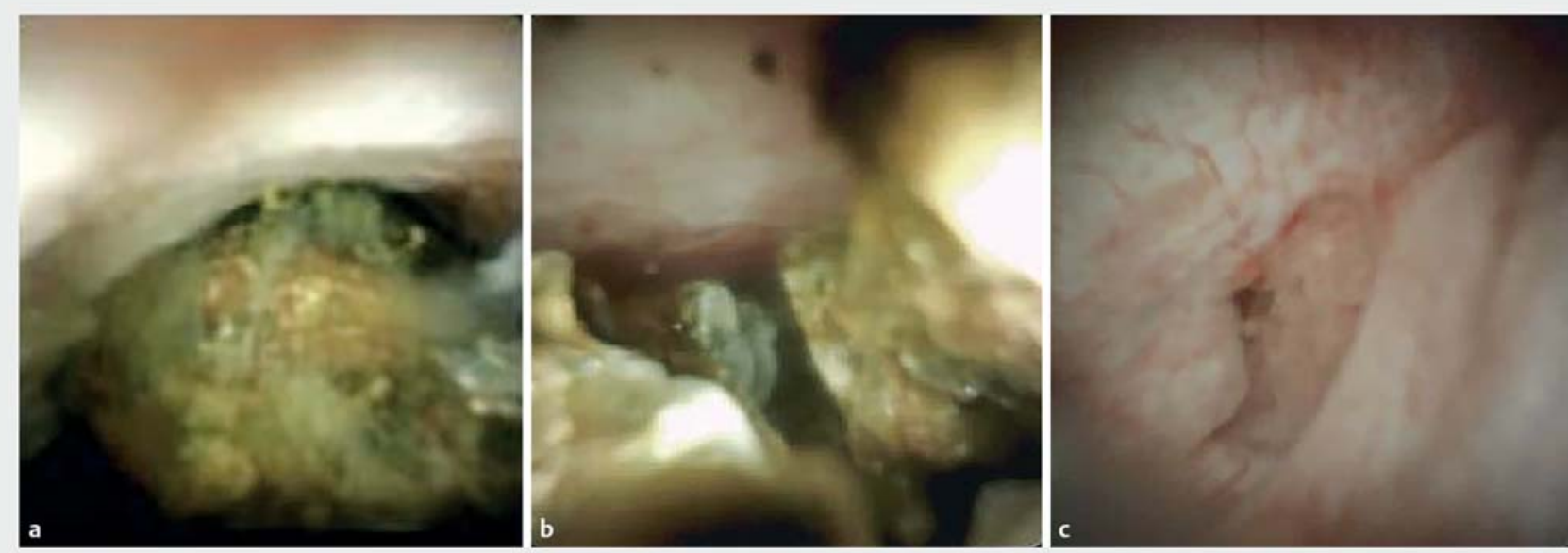

- Fig. 3 a Cholangioscopy with visualization of stone in the cystic duct. b Cholangioscopy showing stone fragments post-EHL. c Cholangioscopy showing cystic duct stump post stone removal.

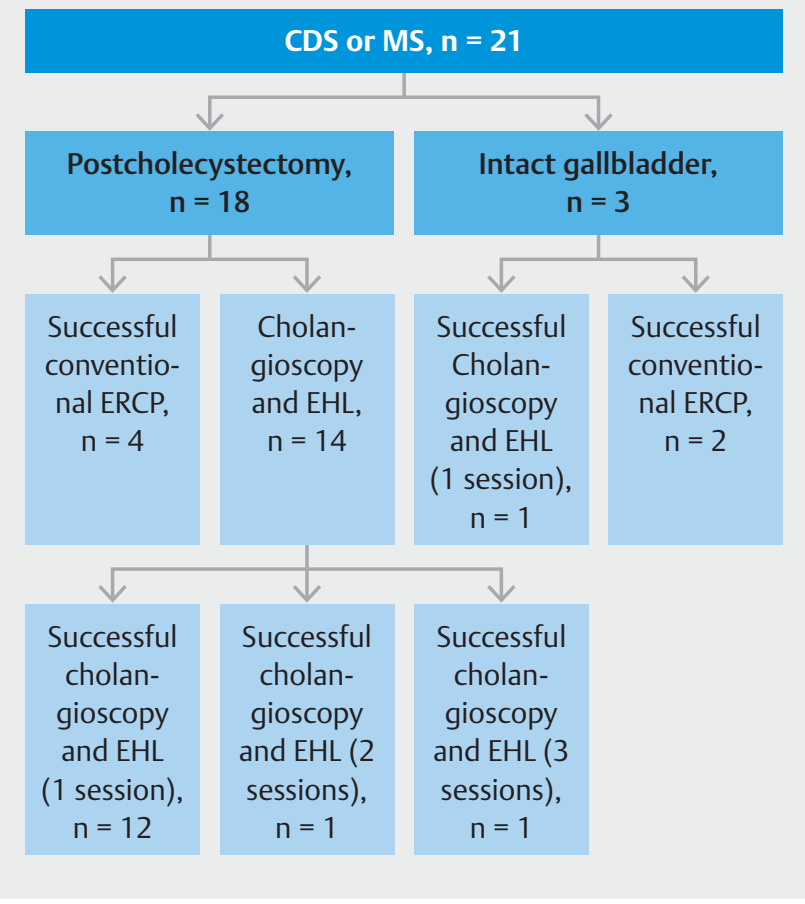

Fig. 4 Flowchart of 21 patients from diagnosis to successful endoscopic management.

( $\triangleright$ Fig.4). $>$ Table 1, $>$ Table 2 , and $\triangleright$ Table 3 describe the demographics, clinical presentation, and outcomes of all patients included in the study.

The mean age of patients treated with cholangioscopy and EHL was 57.2 years (SD 19.3). Eleven patients (11/15, $73 \%$ ) were female. All patients were diagnosed with CDS prior to intervention with either intraoperative cholangiogram (1), ERCP (4), magnetic resonance cholangiopancreatography (7), computed tomography of the abdomen (2), or endoscopic ultrasound (1). The presenting symptoms included abdominal pain
(15), nausea/vomiting (4), and cholangitis (3). Seven patients had hyperbilirubinemia (defined as a bilirubin $>2 \mathrm{mg} / \mathrm{dL}$ ) at clinical presentation. MS was present in three patients (20\%) and concurrent choledocholithiasis was present in six patients (40\%). Fourteen patients had a history of prior cholecystectomy and one patient had an intact gallbladder. The single patient with an intact gallbladder treated with cholangioscopy and EHL had severe cholecystitis at the time of cholecystectomy, which was aborted until resolution of active inflammation was achieved with endoscopic stone removal and cholecystostomy tube placement. Thirteen patients had prior ERCP with sphincterotomy. Eleven patients had one stone present in the cystic duct and four patients had three or more stones ( $\triangleright$ Table 4 ). The median stone size was $10 \mathrm{~mm}$ (range $6-16 \mathrm{~mm}$ ).

In two patients, cholangioscopy showed a fibrotic stricture at the takeoff of the cystic duct preventing passage of the cholangioscope into the cystic duct. Attempts to advance a biliary dilating balloon, biliary dilating catheter, cholangioscopy-guided retrieval basket and snare into the cystic duct were unsuccessful. The patients were given the option of undergoing surgical management for symptomatic retained cystic duct stones; however, opted for endoscopic therapy. On subsequent cholangioscopy, the EHL probe was directed at the stenotic cystic duct orifice and sequential pulses of EHL were delivered at a power of 40 Watts and frequency of $5 \mathrm{~Hz}$. This facilitated stricturotomy and orifice widening ( $\mathbf{F i g} .5$ ). An occlusion cholangiogram was then obtained with opacification of the cystic duct remnant, thereby permitting visualization of stones on fluoroscopy. Under fluoroscopic guidance, an EHL probe was advanced past the stenotic cystic duct orifice and positioned adjacent to the stones. Sequential pulses of EHL were then delivered to achieve stone fragmentation (Boston Scientific, Marlborough, Massachusetts, United States) while using continuous irrigation of saline and contrast. A SpyGlass retrieval basket and snare (Boston Scientific, Marlborough, Massachusetts, United States) were then used to remove the stone fragments. Following stone fragments removal, a plastic stent was placed in the 
흘 产

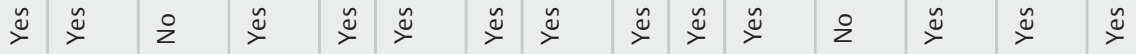

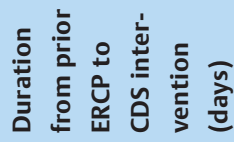

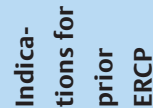

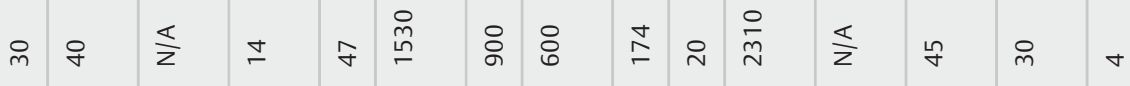

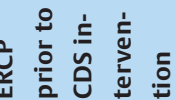

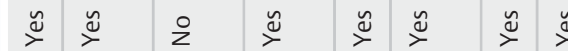

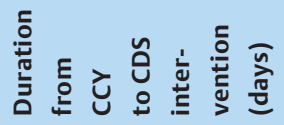

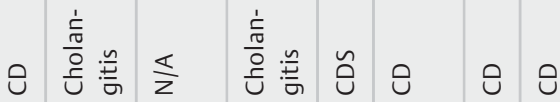

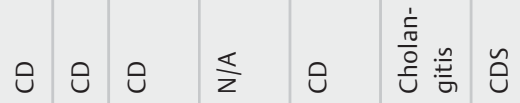

$+\frac{10}{\circ}$

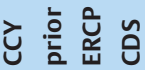

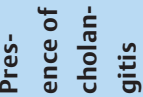

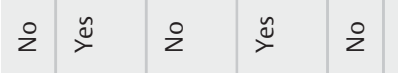

$\frac{n}{4}$
$\frac{5}{0}$
$\frac{\pi}{0}$

$\begin{array}{ll}0 & 0 \\ \tilde{u} & \tilde{u}\end{array}$

ช 8

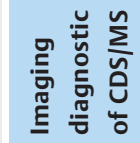

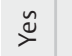

울

$\stackrel{\tilde{y}}{\check{\nu}}$

$\underset{\substack{\infty \\ \dot{m}}}{\substack{\infty \\ m \\ \infty}}$

t)

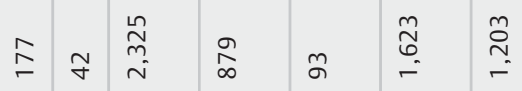

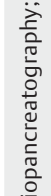

亭

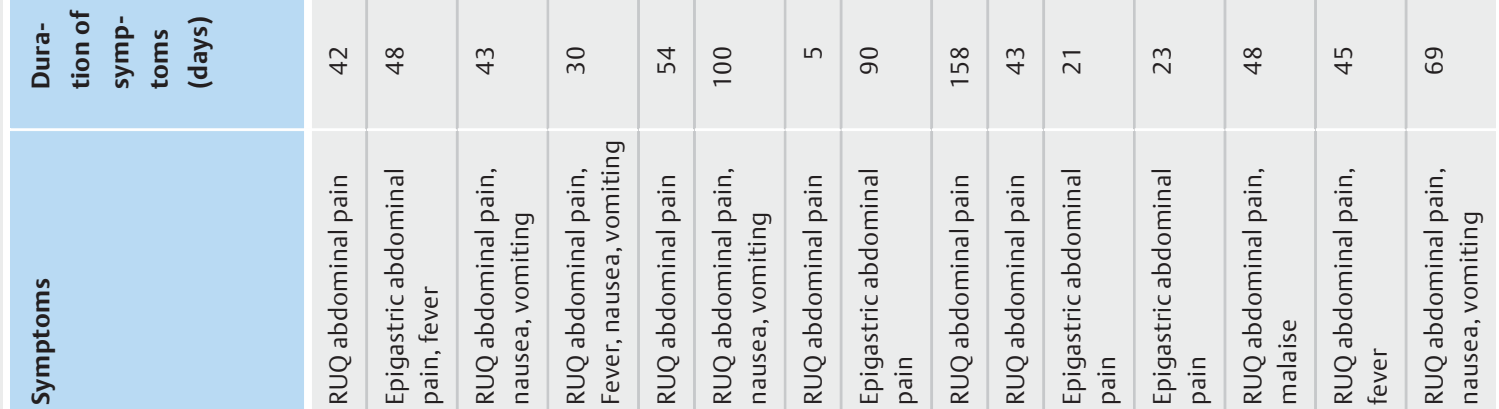

这 ปั

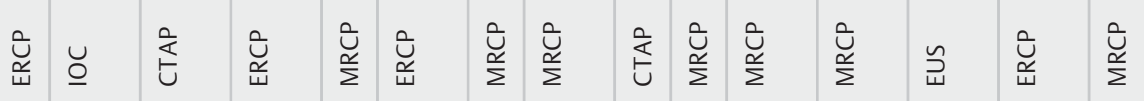

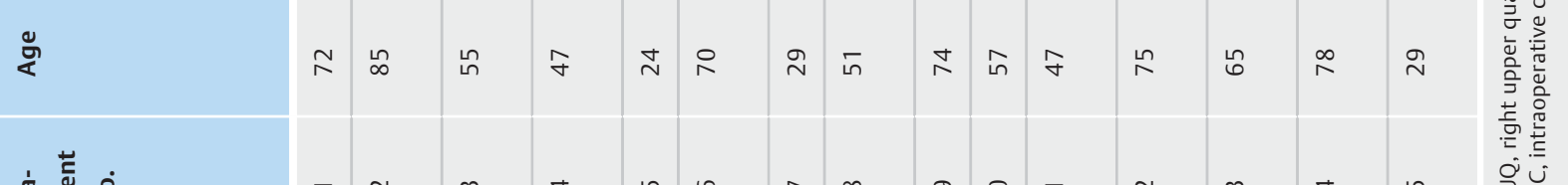




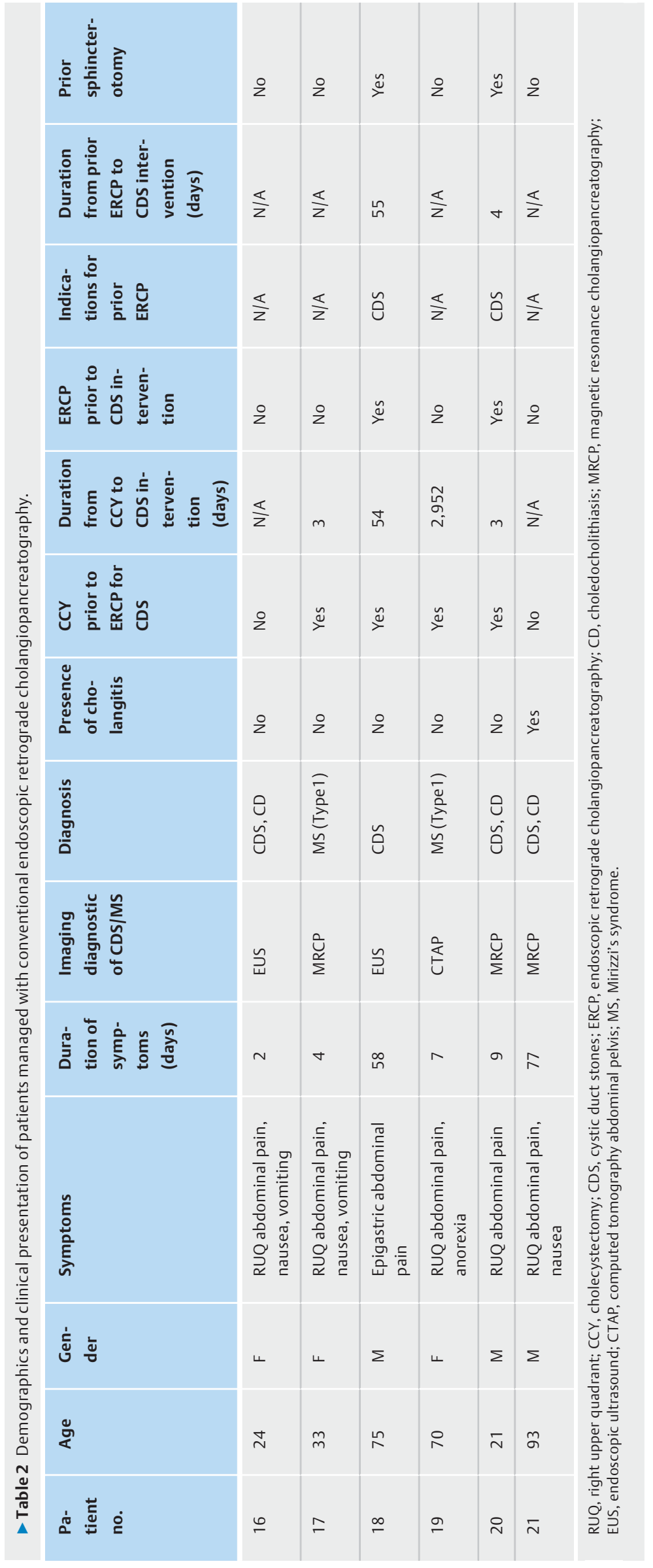




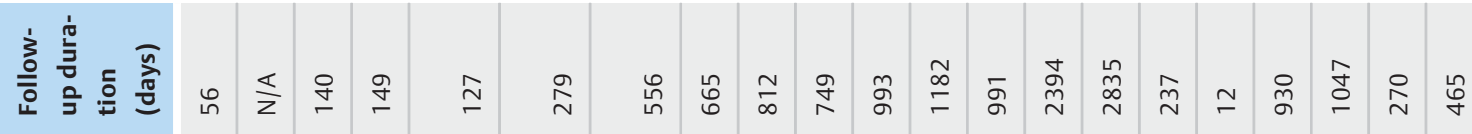

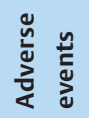

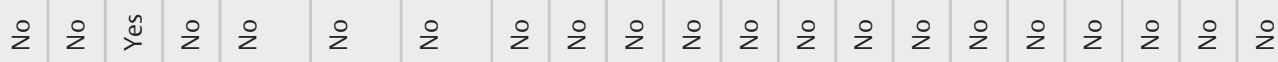

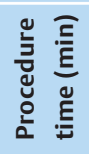

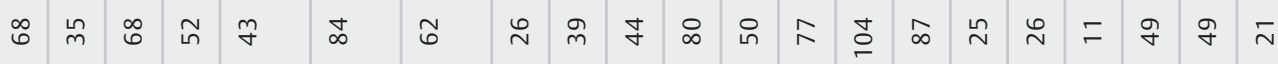

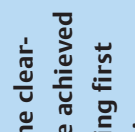

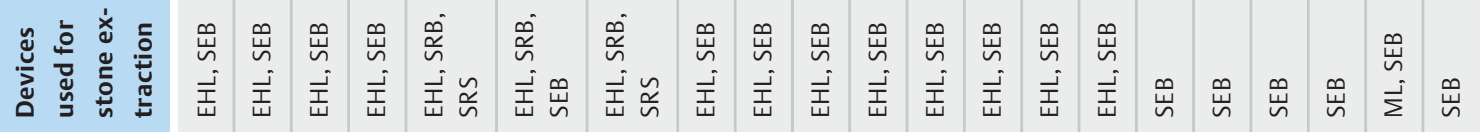

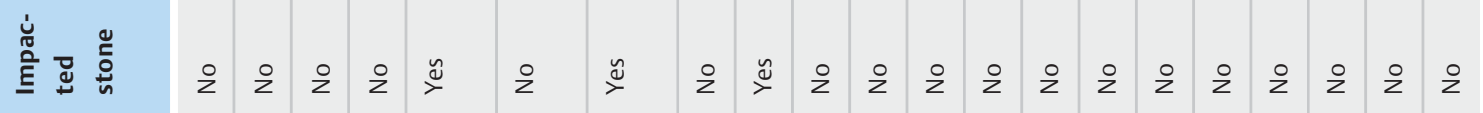

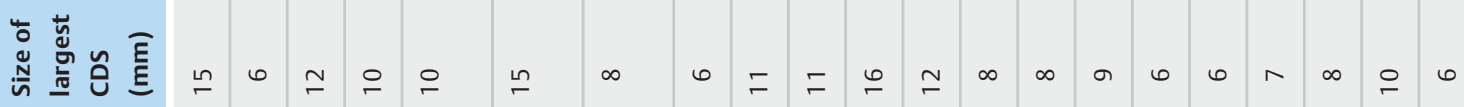
$\stackrel{\tilde{0}}{0}$

产

ஸेँ

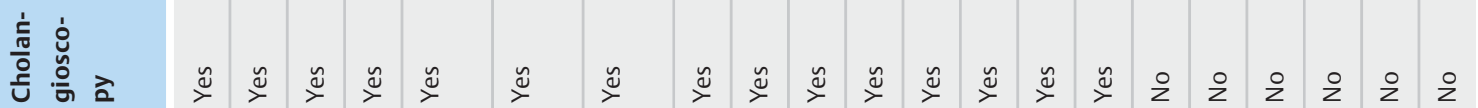

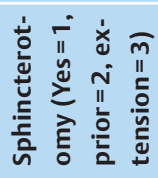

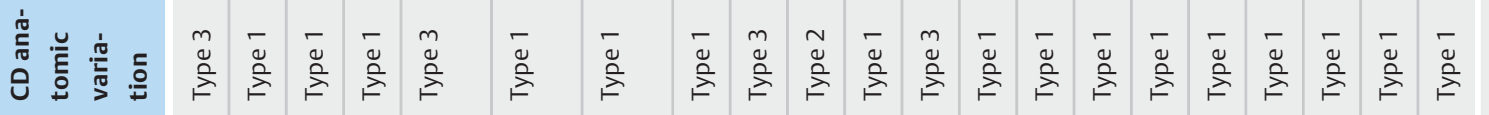

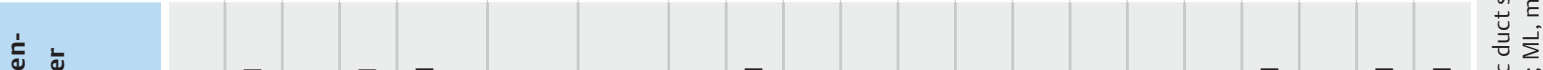

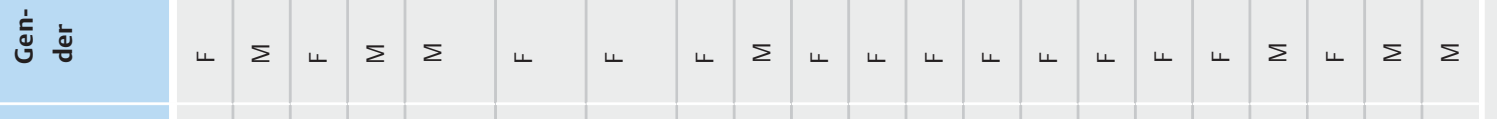

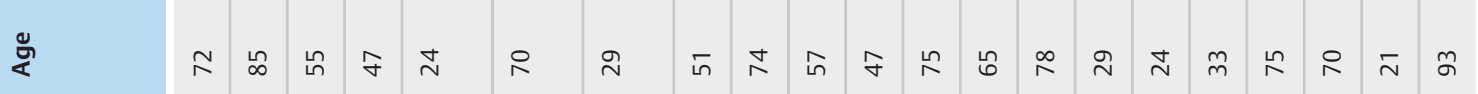

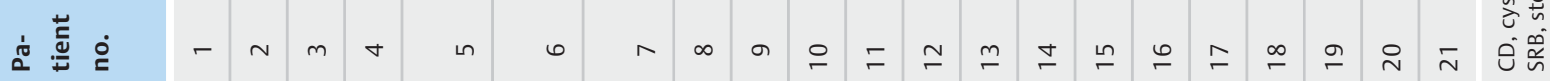



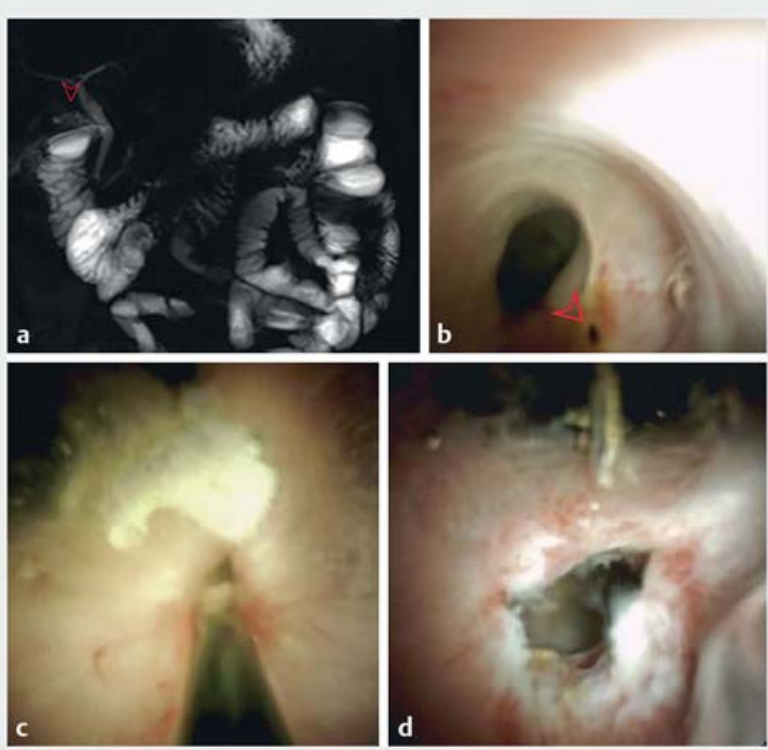

- Fig. 5 a Magnetic resonance imaging of cystic duct stones prior to intervention. b Cholangioscopy showing a stenotic cystic duct orifice. c Stricturotomy using EHL probe directed at the stenotic orifice. d Cystic duct orifice post-stricturotomy.
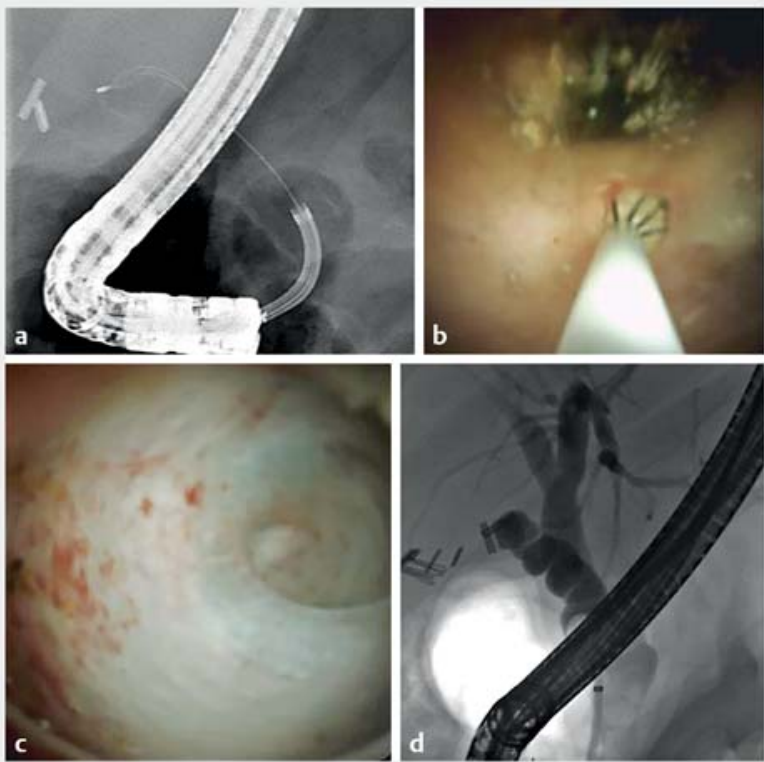

Fig. 6 a Fluoroscopic imaging of a basket in the cystic duct. b Cholangioscopy showing stone fragments removed with a basket. c Cholangioscopic imaging of the cystic duct after stones removal. d Cholangiogram showing a patient cystic duct.

common bile duct. Both patients were discharged on antibiotics the day after the procedure without any complications. On follow-up ERCP(s), cholangioscopy and EHL was performed under direct vision to achieve stone clearance ( $\mathbf{F i g . 6}$ ).
- Table 4 Summary of characteristics of 15 patients undergoing cholangioscopy and electrohydraulic lithotripsy.

\begin{tabular}{|l|l|}
\hline Age, mean $( \pm$ SD), years & $57.2(19.3)$ \\
\hline Female gender, $\mathrm{n}(\%)$ & $11(73 \%)$ \\
\hline Prior cholecystectomy, $\mathrm{n}(\%)$ & $14(93 \%)$ \\
\hline Mirizzi syndrome, $\mathrm{n}(\%)$ & $3(20 \%)$ \\
\hline Concurrent Choledocholithiasis, $\mathrm{n}(\%)$ & $6(40 \%)$ \\
\hline Number of cystic duct stones, median (range) & $1(1-7)$ \\
\hline Number of patients with $\geq 3$ cystic duct stones, $\mathrm{n},(\%)$ & $4(27 \%)$ \\
\hline Median stone size (range), mm & $10(6-16)$ \\
\hline $\begin{array}{l}\text { Number of patients with hyperbilirubinemia at pre- } \\
\text { sentation, } \mathrm{n}(\%)\end{array}$ & $7(47 \%)$ \\
\hline
\end{tabular}

Table 5 Clinical outcomes in 15 patients undergoing cholangioscopy and electrohydraulic lithotripsy.

Successful stone clearance on first session cholangioscopy and EHL, n (\%)

Procedure time for Cholangioscopy and EHL using $1^{\text {st }}$ Gen. SpyGlass, mean $( \pm S D)$, min.

$89.3(13.7)$

Procedure time for Cholangioscopy and EHL using $54.3(18.2)$ SpyGlass DS, mean ( \pm SD), min.

\begin{tabular}{|l|l|}
\hline Patients discharged within 24 hours, $\mathrm{n}(\%)$ & $13(87 \%)$ \\
\hline Adverse events, $\mathrm{n}(\%)$ & $1(7 \%)$ \\
\hline Clinical success, $\mathrm{n}(\%)$ & $15(100 \%)$ \\
\hline
\end{tabular}

Clinical success was achieved in all patients. Post-ERCP pancreatitis occurred in one patient (moderate grade on ASGE lexicon) [7]. This patient was admitted to the hospital for 4 days and her symptoms were managed conservatively with intravenous fluids and pain medications. There were no other procedure or anesthesia-related complications. The average procedure time for patients undergoing first-generation Spyclass was 89.3 minutes (SD 13.7) compared to 54.3 minutes (SD $18.2)$ for SpyGlass DS $(P=0.004)$. Thirteen patients $(87 \%)$ were discharged from the hospital within 24 hours of the procedure ( $\triangleright$ Table 5). The median length of stay for the remaining 2 patients was 2.5 days (range 1-4). The median follow-up was 23.2 months (range 1.8-93.0).

\section{Discussion}

CDS present a challenge to clinicians as they are often difficult to extract via ERCP due to the small diameter of the cystic duct and its tortuous course. Advances in endoscopy, like the development of peroral cholangioscopes in the 1970 s, have provided minimally invasive options for CDS management particularly in patients with prior cholecystectomy [8]. In 2000, Tsuyuguchi et al published a retrospective cohort of patients with MS treated with peroral cholangioscopy and shock wave lithotripsy. In their population of 25 patients, 23 achieved successful stone 
- Table6 Summary of studies utilizing cholangioscopy and EHL/laser lithotripsy for management of CDS and Mirizzi syndrome.

\begin{tabular}{|c|c|c|c|}
\hline First author (year) & No. of patients & Endoscopic technique & Successful stone removal (\%) \\
\hline Tsuguyuchi (2011) & 50 & Cholangioscopy+EHL, LL & $96 \%$ \\
\hline Issa (2011) & 1 & Cholangioscopy $+\mathrm{LL}$ & $100 \%$ \\
\hline Sepe (2012) & 13 & Cholangioscopy + EHL & $77 \%$ \\
\hline Issa (2012) & 2 & Cholangioscopy $+\mathrm{EHL}$ & $100 \%$ \\
\hline Forbes (2016) & 1 & Cholangioscopy $+\mathrm{EHL}$ & $100 \%$ \\
\hline Bhandari (2016) & 34 & Cholangioscopy $+\mathrm{LL}$ & $100 \%$ \\
\hline Jones (2017) & 1 & Cholangioscopy $+\mathrm{EHL}$ & $100 \%$ \\
\hline Marya (2020) & 1 & Cholangioscopy $+\mathrm{EHL}$ & $100 \%$ \\
\hline Li (2020) & 1 & Cholangioscopy + EHL & $100 \%$ \\
\hline Salgado-Garza (2021) & 3 & Cholangioscopy + EHL (2), LL (1) & $100 \%$ \\
\hline Chon (2021) & 1 & Cholangioscopy $+\mathrm{EHL}$ & $100 \%$ \\
\hline Park (2021) & 1 & Cholangioscopy $+\mathrm{EHL}$ & $100 \%$ \\
\hline
\end{tabular}

removal with the cholangioscopic approach; however, longterm outcomes of these patients included cholangitis in four $(17 \%)$ and death in two patients (9\%) [4].

The first cholangioscopes in the 1970 s used a "motherbaby" endoscope technique, which required two trained endoscopists and was limited by poor image resolution and limited accessories. While the mother baby scopes have improved their image quality, the requirement for a second endoscopist has limited its widespread use. The development of SpyGlass (Boston Scientific, Natick, Massachusetts, United States) in 2007 allowed for single-operator cholangioscopy and the use of advanced intervention techniques like lithotripsy (EHL or laser) for management of CDS [9]. While the first-generation SpyGlass improved the endoscopic management of CDS and MS, it was limited by the cumbersome nature of its setup, long procedure times, and poor image quality [10]. Subsequent advances in technology led to the introduction of SpyGlass DS in 2015 with improved visualization of the biliary tree, a wider field of view, and a simple "plug and play" setup $[11,12]$. This innovation has allowed for decreased procedure time and overall ease of use. In fact, Minami et al performed a retrospective study on 183 patients undergoing cholangioscopy using Spyglass DS. Of the 93 patients with indeterminate bile duct strictures, successful visualization and biopsy was achieved in $100 \%$ and $95.7 \%$ respectively. Furthermore, in 90 patients with stone disease, successful visualization of stones was attained in $98.9 \%$ of patients and complete stone clearance in $92.2 \%$ [13].

Since the introduction of cholangioscopy with SpyGlass, a few case reports and case series have demonstrated this method for the management of CDS ( $\triangleright$ Table 6 ) [5, 14-24]. For example, Issa et al. presented the first case of laser lithotripsy using Spyglass cholangioscopy in a patient with postcholecystectomy MS in 2011 [20]. This publication was closely followed by a 2012 case series by Sepe et al, in which 13 patients under- went single operator cholangioscopy and EHL. Complete clearance of the cystic duct was noted in 10 of 13 patients (76.9\%). The high clinical success rate and low AE rate reported by this study demonstrated that SpyGlass with EHL is a viable endoscopic intervention for patients with CDS [21]. Furthermore, Bhandari et al. treated 34 patients with MS or CDS at a high-volume tertiary care center in 2016 with Spyglass and laser-guided lithotripsy with a $100 \%$ success rate [22]. The extensive experience of endoscopists at these centers may partially account for the high success rate associated with these procedures.

An alternative to intraductal lithotripsy for CDS is extracorporeal shock wave lithotripsy (ESWL). This was reported by Shim et al in a case series of 11 patients with impacted CDS who were not surgical candidates [25]. Following disintegration of stones using ESWL, endoscopy was performed to remove stone fragments. Although complete ductal clearance was safely achieved in $81.8 \%$ of patients (9/11), the authors concluded this was a difficult and time-consuming procedure. As a result, widespread dissemination of this technique has yet to be demonstrated.

The traditional treatment modality for CDS in patients with prior cholecystectomy was surgery which has shown limited efficacy and high patient morbidity. In fact, in 2007, Walsh et al reported five post-cholecystectomy patients with CDS requiring surgical intervention. Four patients required laparotomy and only one was successfully treated laparoscopically. This was noted to be secondary to chronic inflammatory tissue and difficulty safely delineating the biliary anatomy [26]. In 2009, Palanivelu et al presented a retrospective cohort of 15 patients with CDS managed laparoscopically. This study demonstrated an average operating time of 103.4 minutes, hospital length of stay of 4 to 12 days, and $13.33 \%$ morbidity [27]. While there was no mortality or conversions to laparotomy, the extended hospital length of stay and significant morbidity pale in com- 
parison to our study results. Most recently, Kar et al published results on 12 patients with cystic duct and remnant gallbladder stones. While seven patients could be managed laparoscopically, five patients required conversion to an open procedure [28]. These studies demonstrate the lack of a viable minimally invasive surgical alternative for these patients.

One of the challenges to successful endoscopic management of CDS in our study was a stenotic cystic duct orifice. This was seen in two patients with a prior history of cholecystectomy and recurrent episodes of stump cholecystitis resulting in stricture formation. Following visualization of stricture on cholangioscopy, an EHL probe was placed in close proximity to the stricture. Oscillating shock waves were then applied to induce epithelial injury and facilitate stricturotomy. This allowed injection of contrast with visualization of stones on fluoroscopy permitting EHL therapy under fluoroscopic guidance. The usage of EHL under fluoroscopic guidance was described by Moon et al in a case series of 19 patients in which 16 achieved complete ductal clearance [29]. In this relatively small case series, there were no episodes of bile leak; however, two patients developed hemobilia. Given the high risk of bile duct injury associated with this technique, we recommend its usage as a last resort.

Our study includes the largest population of CDS patients treated with Spyglass DS to date and reports a $100 \%$ clinical success rate in removing CDS from the biliary tree [23,24]. In addition, it is the largest cohort of CDS patients successfully managed with cholangioscopy and EHL in the United States. There was only one complication observed in our cohort (postERCP pancreatitis), which is a known complication of ERCP. We also report a statistically significant reduction in procedure time with SpyGlass DS compared to first-generation SpyGlass, which is likely a reflection of its improved interface, scope maneuverability, and high-resolution imaging. The limitations of our study include performance by endoscopists with extensive prior experience with cholangioscopy. Therefore, our findings may be challenging to extrapolate to providers without such experience. Given the low prevalence of this disease, this was a retrospective observational study without randomization of patients to a comparison cohort. This may lead to selection bias, preventing generalizability to all patients.

\section{Conclusions}

Our results demonstrate that cholangioscopy and EHL is a safe and effective treatment for management of CDS. Given the shorter procedure times, improved visualization, and high propensity for same-day discharge, we propose that all CDS patients should be evaluated for endoscopic management prior to surgical intervention. Further studies should be performed to evaluate the cost effectiveness of cholangioscopy for CDS and to directly compare a surgical cohort to a SpyGlass DS cohort.
Competing interests

The authors declare that they have no conflict of interest.

\section{References}

[1] Turner MA, Fulcher AS. The cystic duct: normal anatomy and disease processes. Radiographics 2001; 21: 3-22; questionnaire 288-294

[2] Grönroos JM. Mirizzi syndrome: consider endoscopic stone removal. ANZ J Surg 2007; 77: 716-717

[3] Gomez D, Rahman SH, Toogood G] et al. Mirizzi's syndrome-results from a large western experience. HPB (Oxford) 2006; 8: 474-479

[4] Tsuyuguchi T, Saisho H, Ishihara T et al. Long-term follow-up after treatment of Mirizzi syndrome by peroral cholangioscopy. Gastrointest Endosc 2000; 52: 639-644

[5] Jones JD, Pawa R. Single-operator peroral cholangioscopy for extraction of cystic duct stones in postcholecystectomy Mirizzi syndrome. Case Rep Gastrointest Med 2017; 2017: 1710501

[6] Cao J, Ding X, Wu H et al. Classification of the cystic duct patterns and endoscopic transpapillary cannulation of the gallbladder to prevent post-ERCP cholecystitis. BMC Gastroenterol 2019; 19: 1-7

[7] Cotton PB, Eisen GM, Aabakken L et al. A lexicon for endoscopic adverse events: report of an ASGE workshop. Gastrointest Endosc 2010; 71: 446-454

[8] Monga A, Ramchandani M, Reddy DN. Per-oral cholangioscopy. ] Interv Gastroenterol 2011; 1: 70-77

[9] Chen YK, Pleskow DK. SpyGlass single-operator peroral cholangiopancreatoscopy system for the diagnosis and therapy of bile-duct disorders: a clinical feasibility study (with video). Gastrointest Endosc 2007; 65: 832-841

[10] Ishida Y, Itoi T, Okabe Y. Types of peroral cholangioscopy: how to choose the most suitable type of cholangioscopy. Curr Treat Options Gastroenterol 2016; 14: 210-219

[11] Dimas ID, Vardas E, Papastergiou V et al. Comparison of digital versus fiberoptic cholangioscopy in patients requiring evaluation of bile duct disease or treatment of biliary stones. Ann Gastroenterol 2019; 32: 199-204

[12] Menon S, Lekharaju V, Wadsworth C et al. Single Operator Cholangioscopy. Cholangioscopy. 2020: 29-44

[13] Minami H, Mukai S, Sofuni A et al. Clinical outcomes of digital cholangioscopy-guided procedures for the diagnosis of biliary strictures and treatment of difficult bile duct stones: a single-center large cohort study. J Clin Med 2021; 10: doi:10.3390/jcm10081638

[14] Marya NB, Martin JA, Sawas T et al. ERCP-directed electrohydraulic lithotripsy for treatment of cystic duct and remnant gallbladder stones. VideoGIE 2020; 5: 300-303

[15] Li J, Guo S], Zhang JC et al. Novel peroral cholangioscopy-directed lithotripsy using an ultraslim upper endoscope for refractory Mirizzi syndrome: A case report. Medicine 2020; 99: e22649

[16] Chon HK, Park C, Kim TH. Minimally invasive approach using digital single-operator peroral cholangioscopy-guided electrohydraulic lithotripsy and endoscopic nasogallbladder drainage for the management of highgrade Mirizzi syndrome. Clin Endosc 2021: doi:10.5946 ce. 2021.015

[17] Park C, Chon HK, Park DE. Endoscopic treatment including a singleoperator peroral cholangioscopy-guided electrohydraulic lithotripsy and endoscopic nasogallbladder drainage combined laparoscopic cholecystectomy for Mirizzi syndrome. Ann Hepatobiliary Pancreat Surg 2021; 25: S313 
[18] Issa H, Bseiso B, Al-Salem AH. Successful laser lithotripsy using peroral SpyGlass cholangioscopy in a patient with Mirizzi syndrome. Endoscopy 2011; 43: E166-E167

[19] Tsuyuguchi T, Sakai Y, Sugiyama $\mathrm{H}$ et al. Long-term follow-up after peroral cholangioscopy-directed lithotripsy in patients with difficult bile duct stones, including Mirizzi syndrome: an analysis of risk factors predicting stone recurrence. Surg Endosc 2011; 25: 2179-2185

[20] Issa H, Bseiso B, Almousa F et al. Successful treatment of Mirizzi's Syndrome Using SpyGlass guided laser lithotripsy. Gastroenterology Res 2012; 5: 162-166

[21] Sepe PS, Berzin TM, Sanaka S et al. Single-operator cholangioscopy for the extraction of cystic duct stones (with video). Gastrointest Endosc 2012; 75: 206-210

[22] Bhandari S, Bathini R, Sharma A et al. Usefulness of single-operator cholangioscopy-guided laser lithotripsy in patients with Mirizzi syndrome and cystic duct stones: experience at a tertiary care center. Gastrointest Endosc 2016; 84: 56-61

[23] Forbes N, Ishikawa T, Mohamed R. High resolution cholangioscopic electrohydraulic lithotripsy for fragmentation and extraction of impacted cystic duct stones. Endoscopy 2016; 48: E88-E89
[24] Salgado-Garza G, Hernandez-Arriaga P, Gonzalez-Urquijo M et al. Single-operator cholangioscopy and electrohydraulic lithotripsy for the treatment of Mirizzi syndrome. Ann Med Surg (Lond) 2021; 62: 274277

[25] Shim CS, Moon JH, Cho YD et al. The role of extracorporeal shock wave lithotripsy combined with endoscopic management of impacted cystic duct stones in patients with high surgical risk. Hepatogastroenterology 2005; 52: 1026-1029

[26] Walsh R, Ponsky J, Dumot J. Retained gallbladder/cystic duct remnant calculi as a cause of postcholecystectomy pain. Surgi Endosc Other Intervent Techniq 2002; 16: 981-984

[27] Palanivelu C, Rangarajan M, Jategaonkar PA et al. Laparoscopic management of remnant cystic duct calculi: a retrospective study. Annals Royal College Surgeons England 2009; 91: 25-29

[28] Kar A, Gulati S, Mohammed S et al. Surgical management of cystic duct stump stone or gall bladder remnant stone. Indian J Surg 2018; 80: $284-287$

[29] Moon JH, Cha SW, Ryu CB et al. Endoscopic treatment of retained bileduct stones by using a balloon catheter for electrohydraulic lithotripsy without cholangioscopy. Gastrointest Endosc 2004; 60: 562-566 